\title{
Forming a strategy for hospital pharmacy success
}

\section{Richard Price}

"Leaders establish the vision for the future and set the strategy for getting there." John P Kotter

In 2012 it is inevitable that members of the European Association of Hospital Pharmacists (EAHP) will pause for some reflection on the achievements and progress made by the EAHP in its first 40 years. Yet the 40 year milestone is also an opportunity to give thought to the next years-what should be the vision, mission and goals of the EAHP going forward to 2020 and beyond, and what will it mean to be a hospital pharmacist by that time?

With those questions in mind, the EAHP's Board of Directors recently took 2 days out in January to hold a considered discussion on the future and on strategy.

Up for discussion were a broad range of matters including:

Correspondence to Richard Price, Policy and Advocacy Officer, European Association of Hospital Pharmacists (EAHP), Rue Abbé Cuypers, 3, B - 1040 Brussels, Belgium; po@eahp.eu
- The definition of what it means to be a hospital pharmacist now and in the future

- The future role of hospital pharmacist to get the best outcomes for patients

- The representative role of the EAHP, what this should be comprised of and how it should be enacted

- The evolution of the EAHP's educational and developmental role

- The key stakeholders for the Association and how to involve and interact with them in relation to these roles

- The need to continually engage member associations in the principal activity

- How best to measure results

Over the weekend a number of

conclusions, and changes to the EAHP goals, future activities and reporting structures were agreed, and the main recommendations will be taken to the General Assembly of the Association in June.

In addition to this, many other wider questions were opened for which further deliberations with members and other stakeholders will take place before finding and settling the answers. This is particularly the case in relation to giving more shape and definition to the desired future destination of the hospital pharmacy profession.

In summary, it has been said that the future belongs to those who prepare for it today. Hospital pharmacists across Europe are encouraged to take ownership of their profession and of its future.

In the year ahead, the EAHP will be opening this question for debate and readers of the European Journal of Hospital Pharmacy are urged to stay alert for news on how they can take part. We look forward to your participation.

Competing interests None.

Provenance and peer review Not commissioned; not externally peer reviewed.

Accepted 25 January 2012

European Journal of Hospital Pharmacy

2012;19:5-6.

doi:10.1136/ejhpharm-2012-000082

\section{Hospital pharmacy specialisation \\ Hospital pharmacists currently undertake a diversity of roles in the health care system. There are constant innovative changes being made to the pharmacists' role to ensure the safe and effective use of medicines.}

With the European Directive 2005/36/EC, the European Authorities have set a basic degree of university pharmacy study. Unfortunately, this basic degree doesn't provide sufficient qualifications for the independent work of a Hospital Pharmacist.

The EAHP, in response to the expectations of its members and related professionals, is proposing a complementary structured specialized education in this very specific field, which is to be inserted in the Directive.

To achieve a high quality of pharmacy care for patients in the hospital environment, a standardised level of formation, and a flexible labour market, EAHP is working hand in hand with PHARMINE and FIP, and assisted in the development of a "Hospital Pharmacy Outcomes" (HPO) and the PHARMINE structure.

$\mathrm{HPO}$ provides a list of professional competencies necessary for the specialized practice of hospital pharmacy that are to be expected from intermediate pharmacists after completion of a period of work or training in a hospital setting. 


\section{Statement on Hospital Pharmacy specialisation}

Hospital Pharmacists are key stakeholders in medication management in hospitals. This is a role which encompasses the entire way in which medicines are selected, supplied, quality assured, prescribed, and administered with the overall aim being to improve the safety and quality of all medicine related processes affecting patients.

To achieve this, a hospital pharmacist must be able to operate in a complex hospital setting and work collaboratively within multidisciplinary healthcare teams in order to provide the best treatment for patients in acute situations or receiving care in specialised ambulatories.

The basic education of 5 years for pharmacists as required by the European Directive on Mutual Recognition of Professional Qualifications 2005/36/EC does not provide sufficient competencies to work independently in the hospital environment. Additional competencies are necessary to fully understand the processes in hospitals and to manage the specific requirements of certain patient groups (i.e. paediatrics, oncology, intensive care, rare diseases.) A comprehensive list of the competencies necessary to improve hospital pharmacy outcomes has been produced by EAHP with the support of the EU funded Pharmine project (http://www.eahp.eu/Advocacy/Hospital-pharmacyspecialisation).

EAHP believes that post graduate education in the hospital setting of at least 3, preferably 4 years with a final assessment of individual competency is essential to ensure that where pharmacists are providing front office hospital pharmacy services, patients benefit from the highest levels of expertise.

Many EU Member States have already formally recognised the need for specialisation in hospital pharmacy and the way in which this improves patient care. However, a lack of EU level mutual recognition of Hospital Pharmacy as structured specialisation creates substantial differences in the qualifications of pharmacists working in hospitals across Europe. It also undermines the efforts of certain European countries to advance the level of pharmaceutical care in the hospital setting and creates inequalities in patient access to the best possible care.

The review of the EU Directive on Mutual Recognition of Professional Qualifications provides an opportunity to address these issues. As an advocate of patient safety and in particular the safe and effective management of medication in hospitals, EAHP firmly asks that the European rules on professional mobility be updated to introduce Hospital Pharmacy as a mutually recognised speciality. This should be done in a way which is comparable to what has already been implemented for physicians under similar conditions. We believe that this is an essential step forward to ensure that all patients in acute situations benefit from pharmaceutical care that is underpinned by the highest levels of knowledge, skills, and experience. 